\title{
Fatores associados à corrupção municipal em transferências de recursos da União
}

Factors associated with municipal corruption on union resources transfers

\section{Abstract}

This article assesses the tendency to municipal corruption based on counting models, which have as response variables the findings recorded in 1600 audit reports of the Controladoria-Geral da União, CGU, referring to the Brazilian municipalities. The sensitivities of these irregularities were estimated an tested as a function of the volume of resources inspected, to their stage of development, to the role of social control, to its demographic characteristics, to the contagion effect among neighboring municipalities, to the second mandate of the mayor and his political party. The results have shown that the municipalities with medium and severe findings are those that receive a high percentage of resource transfers, they also have weak social control and a low level of municipal development, they are not sparsely populated and have neighboring municipalities with corruption problems. Sixteen medium irregularities and six serious irregularities are found of every $\mathrm{R} \$ 100 \mathrm{mil}$ lion of resources received by a municipality.

\section{Keywords}

municipal corruption; resource decentralization; count models.

JEL Codes D73, H11, H77.

\author{
Francisco de Assis Oliveira Campos (1) \\ Ivan Castelar (2) \\ Ricardo Brito Soares (3) \\ (1) Controladoria Regional da União do Ceará \\ (2) Universidade Federal do Ceará \\ (3) Universidade Federal do Ceará
}

\section{Resumo}

O presente artigo avalia a probabilidade de ocorrência de corrupção municipal a partir de modelos de contagem, tendo como variáveis de interesse os achados irregulares de fiscalização considerados médios e graves, extraídos de 1600 relatórios da Controladoria-Geral da União-CGU referentes aos municípios brasileiros. Foram estimadas e testadas as sensibilidades destas irregularidades ao volume de recursos fiscalizados do município, ao seu estágio de desenvolvimento, à atuação do controle social, a sua caracterização demográfica, ao efeito contágio de um município limitrofe corrupto, ao caso de segundo mandato do prefeito e ao seu partido político. Os resultados mostraram que as irregularidades tendem a aumentar nos municipios com maiores volumes de recursos recebidos, quando o controle social tem fraca atuação, quando o mesmo possui baixo desenvolvimento e alta densidade demográfica, e são vizinhos de municípios com problemas de corrupção. Dezesseis irregularidades médias e seis graves são encontradas a cada $R \$ 100$ milhões de recursos recebidos por um municipio.

\section{Palavras-chave}

corrupção municipal; descentralização de recursos; modelo de contagem.

Códigos JEL D73, H11, H77. 


\section{Introdução}

A corrupção tem se mostrado um fenômeno globalizado, embora com maior predominância em regiões pobres e em desenvolvimento (GLIYM et al., 2002: ROSE-ACKERMAN, 2002), principalmente devido à fragilidade das instituições dessas regiões, a qual cria oportunidades para o surgimento de problemas de agente-principal e comportamento rent-seeking, principalmente pelo fato que a corrupção ocorre na interface dos setores público e privado (ROSE-ACKERMAN, 2002). Pesquisas empíricas também têm demonstrado que o risco de exposição à corrupção é ampliado com o baixo nível de renda per capita e de escolaridade, de instabilidade política e de diversidade étnica (MAURO, 1995; BARDHAN, 1997; TANZI, 1998; LAMBSDORFF, 2003; ROSE-ACKERMAN, 1978; SHLEIFER, VISHNY, 1993 e EASTERLY, 2004).

Os impactos econômicos negativos da corrupção têm recaído sobre o investimento e o produto (MAURO, 1995; BARDHAN, 1997; TANZI, 1998, BARRO; SALAI-I-MARTIN, 2004, EASTERLY, 2004). Ademais, Kaufmann et al. (2003) afirmam que a corrupção tem se mostrado um imposto regressivo para o pobre, o qual acaba pagando com uma parcela desproporcional da sua renda em propinas para usufruir de serviços básicos, tendo um acesso reduzido à saúde, à educação, além de outros serviços.

De acordo com Svensson (2005), a estimativa anual do Banco Mundial para a corrupção gira em torno de um trilhão de dólares americanos, ou algo próximo a 3\% do PIB mundial; o que denota, mesmo considerando problemas de medição, quão sério é o problema para a economia e a sociedade. Especificamente para o Brasil, as pesquisas empíricas e as estimativas realizadas demonstram que a corrupção é bastante significativa no País. O Índice de Percepção de Corrupção da Transparência Internacional relativo ao Brasil apresenta-se em média 3,8 para o período entre 1995 e 2010, o que coloca o país entre as nações de índice de corrupção preocupante.

Basicamente, as pesquisas econômicas sobre o assunto têm utilizado dados agregados e concentram-se em variações cross-country, por meio de índices de percepção (por exemplo, o Índice de Percepção de Corrupção da Transparência Internacional), sujeitando-se a críticas tanto devido a possíveis vieses inerentes às características desse tipo de indicador, composto e subjetivo, quanto pela complexidade de um conceito que sirva para um 
conjunto de países, ver DONCHEV; UJHELYI (2014), MOCAM (2004), KNACK (2006), OLKEN (2009) e Thompson e SHAH (2005).

Alternativamente, têm sido utilizadas medidas diretas para avaliar o nível de corrupção em programas e projetos públicos executados em localidades específicas, por exemplo: Ferraz; FINAN (2011, 2012), usam microdados obtidos de relatórios de fiscalização, já OLKEN (2009) e Reinikka e SVENSSON (2003) adotam técnicas de rastreamento de gastos públicos. Os resultados dessas pesquisas têm mostrado que, em termos de efeitos locais e de curto prazo, a corrupção é significativa e prejudica diretamente as classes sociais de baixa renda, à medida que o volume de recursos formalizados nos orçamentos não são aplicados de acordo com o que estava previsto nos projetos, ocorrendo desvios tanto de recursos financeiros como de materiais, influenciando negativamente as metas estabelecidas no planejamento orçamentário.

De acordo com o Tribunal de Contas da União - TCU (2011), em termos médios, no período 2007-2010, somente as transferências voluntárias de recursos federais alcançaram $\mathrm{R} \$ 25,9$ bilhões. Além disso, a complementação do FUNDEB, em 2011, que não está inclusa no volume de transferências voluntárias, foi da ordem de R \$ 6,4 bilhões, segundo a STN/MF. Assim, a esfera municipal apresenta-se como um objeto de estudo importante para se examinar a tendência à corrupção e os prejuízos econômicos e sociais que o fenômeno da corrupção acarreta ao país, tendo em vista que são os municípios os executores dos programas sociais básicos nas áreas da educação fundamental e básica, saúde e infraestrutura urbana e rural ${ }^{1}$.

O Programa de Fiscalização por meio de Sorteio Público dos Municípios Brasileiros da CGU foi adotado a partir de 2003 com o objetivo de examinar a eficiência e a efetividade das aplicações de transferências de recursos federais - exceto o fundo de participação dos municípios -pelos municípios brasileiros. Na 30a edição do Programa, outubro de 2010, que envolveu recursos da ordem de $\mathrm{R} \$ 830$ milhões, os relatórios registraram problemas graves em 57 dos 60 municípios fiscalizados, tais como: montagem irregular dos processos licitatórios e vínculos familiares entre lici1 No Brasil, as transferências são classificadas como constitucionais, legais e voluntárias, de acordo com o mandamento e a regra de liberação. Conforme a Lei de Responsabilidade Fiscal, as transferências voluntárias são definidas como a entrega de recursos financeiros a outros entes da federação, a título de cooperação, auxílio ou assistência financeira, que não decorra de determinação constitucional, legal, nem seja destinada ao Sistema Único de Saúde. 
tantes e o prefeito municipal, fraudes em licitações, desvios de recursos e equipamentos, prática de sobrepreço e pagamentos de serviços não realizados (CAMPOS, 2012).

Portanto, a partir dos registros de irregularidades constantes dos relatórios de fiscalizações e das pesquisas realizadas por Campos; Pereira (2016), Carraro et al. (2006), Ferraz; Finan (2011), dentre outras, é razoável supor que a corrupção municipal no Brasil apresenta níveis consideráveis e vem repercutindo na qualidade dos serviços públicos prestados pelos municípios. Daí a importância da identificação dos fatores propícios à corrupção municipal com vistas a determinar estimativas de incidência nos municípios brasileiros, bem como sugerir políticas para o melhor controle dessa atividade ilícita; o que, por fim, repercutiria no aumento da eficiência dos recursos públicos.

Especificamente, o objetivo do presente trabalho é estimar por meio de modelos de contagem o impacto de um conjunto de variáveis sobre a probabilidade de que determinado município brasileiro cometa irregularidades na gestão dos recursos federais transferidos por meio de convênios, acordos, contratos de repasse e transferências legais². Para isso, a base de dados para as variáveis de contagem foi construída a partir das irregularidades identificadas em 1600 relatórios de fiscalização da CGU, referentes ao período de 2003 a 2010, sendo as mesmas diferenciadas entre irregularidades formais, médias ou graves. Este tratamento das irregularidades de maneira tipificada em graves e médias e na sua frequência de ocorrência (contagem), juntamente com uma base de dados mais ampliada das fiscalizações da CGU, são as principais contribuições deste artigo para a literatura e estudo da administração pública ${ }^{3}$.

Em primeiro lugar deseja-se investigar como o volume de recursos voluntários e legais transferidos pela união para os municípios influencia o montante das irregularidades médias ou graves, dado que estas são aproximações, e por vezes coincidem com a própria evidência de corrupção

2 O Fundo de Participação dos Municípios (FPM) entrará apenas como uma covariável do tipo controle, pois não foram fiscalizadas, de forma separada, as despesas que tiveram essas transferências como fonte de recursos, cuja competência de fiscalização é do tribunal de contas dos municípios/estados.

3 Como será especificado adiante, Ferraz et al. (2012), Ferraz; Finan (2011) Brollo et al. (2013), e Albuquerque; Ramos (2006) trabalharam com um base de dados bem menor, 365, 365, 606 e 530 municípios respectivamente, sendo que Ferraz; Finan (2011) e Albuquerque; Ramos (2006) também trabalharam com variáveis de contagem, mas a tipificação das irregularidades não foi discriminada entre média e grave. 
no município. Pretende-se, especificamente neste aspecto, medir a sensibilidade com que maiores volumes de recursos recebidos transformam-se em maiores oportunidades para irregularidades na administração e uso do recurso público.

Adicionalmente, outros fatores contextuais, institucionais, e de fiscalização podem também influenciar o comportamento ilícito do prefeito e dos seus principais auxiliares. Entre outros fatores citados pela literatura estão aqueles relacionados no âmbito do desenvolvimento econômico e social (Índice Firjam), e demográfico (densidade demográfica), ao controle social por parte da população (presença de conselho social atuante), ao efeito contágio de municípios vizinhos (fronteira com município com irregularidades) e a fatores políticos (segundo mandato e partido dos prefeitos).

Uma descrição mais detalhada tanto da variável dependente de irregularidades municipais encontradas pela CGU, como também dos potenciais efeitos das variáveis explicativas mencionadas, serão os temas respectivos das seções que se seguem a partir desta introdução. A metodologia de estimação destes efeitos será descrita na quarta seção. Os resultados encontrados são reportados e analisados na seção cinco. Finalmente, estes e outros resultados constroem a base para inferências políticas, fiscais, e metodológicas que possam contribuir para o estudo deste problema crônico.

\section{Irregularidades municipais}

O Programa de Fiscalizações de Municípios a partir de Sorteios Públicos foi criado em junho de 2003 pela Controladoria Geral da União, com o intuito de aumentar o rigor de fiscalização das transferências da União para os municípios. A metodologia do programa consiste em sortear periodicamente 60 municípios brasileiros dentre aqueles com até 500 mil habitantes, para fins de fiscalizar a execução nos municípios dos programas que utilizam recursos federais. Enquadram-se nesta definição os recursos de transferências legais (FUNDEB/FUNDEF, PNAE, PNATE, entre outros) e voluntárias (convênios e contratos de repasse), bem como os recursos de programas federais executados por entidades estaduais e federais no município sorteado (tais como Pronaf, FNE, incentivos fiscais e outros), trans- 
feridos e executados nos últimos dois anos ${ }^{4}$. Até dezembro de 2010, foram realizados 33 Sorteios e fiscalizados quase 1.800 municípios, cobrindo um montante de recursos da ordem de $\mathrm{R} \$ 15$ bilhões.

Outras pesquisas já foram realizadas a partir dos registros dos achados desse Programa de Fiscalização. Ferraz et al. (2012), por exemplo, construíram medidas de corrupção municipal a partir dos achados de fiscalização em 365 municípios, considerando 10 eventos de sorteios públicos realizados pela CGU, no período de 2003 a 2005, com o fito de analisarem os efeitos negativos da corrupção sobre a gestão e o desempenho educacional nos municípios brasileiros.

Na mesma linha, Ferraz; Finan (2011) usaram os dados dos relatórios de fiscalização para construírem novas medidas de corrupção política nos municípios e testarem se há efeitos sobre as reeleições dos prefeitos municipais.

Brollo et al. (2013), verificaram um aumento da corrupção municipal e os efeitos eleitorais em face do recebimento de transferência de recursos excepcionais, um tipo de "the political resource curse", utilizando uma base de dados composta por 606 municípios, considerando 17 eventos de sorteios públicos realizados pela CGU no período de 2003 a 2007.

Albuquerque; Ramos (2006) também elaboraram uma base de dados a partir do Programa de Fiscalização da CGU, usando 503 municípios, para examinarem o comportamento ilícito dos prefeitos municipais no gerenciamento dos recursos transferidos pela União.

De forma mais ampla, utiliza-se na presente pesquisa uma base de dados composta de 1600 dos 1822 relatórios gerados para o período de 2003 a 2010, abrangendo 30 eventos de sorteios públicos do programa da CGU, no sentido de verificar o poder de explicação de um conjunto de variáveis sobre a conduta ilícita da administração municipal. Além de um maior conjunto de informações, a metodologia de classificação dos achados é diversa da utilizada por Ferraz et al. (2012) e Ferraz e Finan (2011), que identificaram as irregularidades considerando apenas três tipos de práticas corruptas; ou seja, desvios de recursos públicos, sobrefaturamento e irregularidades em licitação, sem classificá-las em graves, médias e formais, como acontece no presente artigo ${ }^{5}$. Também é diferente de Brollo consideração de que os eventos podem ocorrer de forma independente, representando falhas 
et al. (2013), que classificou as irregularidades em dois tipos: larga (inclui práticas de má administração) e estreita (considera apenas as irregularidades, identificadas a partir de práticas de desvios, fraudes em licitação e sobrefaturamento) ${ }^{6}$.

Com base nas normas e práticas de auditorias aplicáveis ao serviço público federal, os auditores emitem seus relatórios, destacando os achados de auditorias (indícios e evidências de atos irregulares praticados pelos gestores ou outros agentes) ${ }^{7}$. Conforme já especificado anteriormente, para fins de classificação dos achados à luz das suas contribuições para a existência de situações de corrupção no âmbito do município, considerou-se neste trabalho apenas os recursos federais decorrentes de transferências legais e voluntárias dos programas com ações de execução direta ou indireta das prefeituras municipais. Com isso, foram excluídos os programas executados diretamente pelas autarquias federais, pelos bancos públicos (FNE, PROGER, FGTS, Pronaf, entre outros), pelas autarquias estaduais e outras entidades não vinculadas às prefeituras ${ }^{8}$.

Considerando essa metodologia de registro do ponto de auditoria adotada pela CGU, a classificação utilizada para definição da variável dependente se constitui no fato do achado de auditoria/fiscalização sinalizar uma situação de corrupção, no sentido de que o agente público municipal está usando a sua função para tirar proveito da situação em benefício próprio. Assim, espera-se que essa proxy, além de ter uma forte correlação com as situações de corrupção, capte também o comportamento do agente incentivado por diversos fatores (que estão relacionados à oportunidade e aos mecanismos de incentivos e punição à la BECKER (1968), bem como

diferenciadas no sistema de controle e gestão municipal.

6 Ressalta-se que Albuquerque; Ramos (2006) não explicitaram em seu trabalho qualquer separação quanto ao tipo de irregularidade considerada.

7 Os achados incluem critérios ou bases para determinar que tipo de problema existe, a condição ou situação que foi observada, o efeito ou impacto da condição e a causa do problema e sua extensão. Os achados devem resultar em recomendações que resolvam os problemas, que possam eliminar as causas e os impactos que os atos irregulares geraram. Na prática, achados são as constatações de fiscalizações/auditorias às quais se caracterizam como irregularidades/falhas graves, médias, formais e administrativas.

8 Os recursos transitados no município por meio desses órgãos e fontes não requer participação direta dos gestores municipais. Por exemplo, o INSS, autarquia, executa suas atividades no município sem nenhuma interferência dos gestores privados. No caso dos recursos advindos das instituições financeiras, o processo de concessão de crédito decorre de condições definidas por normas legais e práticas de mercado cuja observância cabe a instituição financeira, inclusive com classificação de risco para as concessões acima de $\mathrm{R} \$ 35.000,00$. 
a insuficiência de controles internos e fragilidades institucionais. Em cada ciclo político a administração pública vigente encontra uma situação mais ou menos favorável à ação corrupta e age de acordo cometendo mais ou menos irregularidades. Os critérios de classificação usados nesta pesquisa para discriminar estas irregularidades foram os seguintes:

\section{a) Achados Graves:}

Fraude, sobrepreço, sobrefaturamento, desvios (não execução do objeto), irregularidades graves no processo licitatório (tais como conluio e montagem de processo licitatório, contratação direta com evidências de direcionamento, beneficiamento entre outras falhas graves). A ocorrência desses ilícitos na execução de uma despesa pública está relacionada a um ato corrupto.

\section{b) Achados Médios:}

Falhas na execução dos processos licitatórios e na execução de contratos que contrariam a legislação vigente e que podem contribuir diretamente para a ocorrência das irregularidades graves, tais como: ausência de publicação de atos relevantes (alterações de editais), restrição à competitividade, ausência de orçamento detalhado, de pesquisa de preço, ausência de fiscalização da execução do contrato e de boletins de medição.

\section{c) Achados Formais}

Falhas decorrentes da não observação dos aspectos formais da legislação que não geram, individualmente ou em conjunto, repercussões significativas sobre o resultado da aquisição ou contratação. Normalmente, decorrem de ineficiências e problemas administrativos, tais como: pessoal desqualificado para as atribuições, ausência de sistema de informação, de material e equipamento, dentre outras.

Para fins de ilustração, o quadro a seguir mostra alguns achados graves, médios e formais concebidos a partir dos registros dos pontos de auditoria constantes de um Relatório de Fiscalização da CGU. 
Quadro 1 Exemplo de Constatações (Graves, Médias e Formais)

\begin{tabular}{|c|c|}
\hline $\begin{array}{l}\text { Classificação } \\
\text { dada aos re- } \\
\text { gistros* }\end{array}$ & $\begin{array}{l}\text { Pontos de Auditoria registrados no Relatório } n^{\circ} 01640,10 / 05 / 2010 \\
\text { Município de Alegrete/PI, cujo valor total fiscalizado foi de R\$ 5.008.087,36 }\end{array}$ \\
\hline Achado Grave & $\begin{array}{l}\text { 1. Fraude realizada no processo licitatório n }{ }^{\circ} 003 / 2009 \text {, referente à contratação } \\
\text { de empresa de serviços de engenharia para execução de reforma e ampliação das } \\
13 \text { escolas do município. } \\
\text { 2. Pagamentos por reformas em escolas com recursos do FUNDEB, sem que os ser- } \\
\text { viços contratados tenham sido efetivamente executados, no valor de } \mathrm{R} \$ 38.616,60 \text {. }\end{array}$ \\
\hline Achado Médio & $\begin{array}{l}\text { 1. Irregularidades na realização da Tomada de Preços nº 002/2010, referente à } \\
\text { contratação de veículos de terceiros destinados ao transporte de estudantes do } \\
\text { município, no valor contratado de } \mathrm{R} \$ 177.771,51 \text {. } \\
\text { 2. Irregularidades na realização dos Convites } n^{\circ} 16 / 2009,17 / 2009 \text { e } 18 / 2009 \text {, } \\
\text { referentes à locação de veículos tipo ônibus e van para o transporte de alunos do } \\
\text { município. }\end{array}$ \\
\hline Achado Formal & $\begin{array}{l}\text { 1. Condições inadequadas do armazenamento dos produtos da merenda. } \\
\text { 2. Falha na formalização de contrato, não identificando o preço por quilômetro } \\
\text { rodado. }\end{array}$ \\
\hline
\end{tabular}

Fonte: Elaborada pelo autores

${ }^{*}$ Classificação realizada pelos autores.

Após tipificar e quantificar os achados de auditoria em graves, médios ou formais (ineficiências), esse trabalho selecionou para fins de contagem apenas os primeiros tipos de irregularidades (graves e médias) dado que os mesmos são maiores aproximações do comportamento corrupto. Ainda assim, as irregularidades médias e graves foram tratadas de maneiras isoladas, considerando que os eventos podem ocorrer de forma independente, representando falhas diferenciadas no sistema de controle e gestão municipal. Este tratamento das irregularidades de maneira tipificada (graves e médias) e na sua frequência de ocorrência (contagem), juntamente com uma base de dados mais atualizada das fiscalizações da CGU, são as principais contribuições deste artigo para a literatura e o estudo da administração pública.

\section{Determinantes municipais das irregularidades}

A literatura teórica e empírica sobre corrupção destaca um conjunto de fatores que podem, a priori, influenciar o comportamento ilícito das pessoas individualmente, ou como agentes responsáveis por recursos públicos. 
A base conceitual para o modelo empírico tem os gestores municipais como unidade de decisão iniciando o seu ciclo político, no qual a racionalidade econômica, principalmente quanto aos riscos envolvidos e as recompensas extraídas, junto com as oportunidades propiciadas pelo ambiente burocrático e político, incentivando o comportamento corrupto. Ou seja, ao tomar posse, o prefeito encontra um contexto que pode favorecer a conduta irregular no seu curto espaço temporal de ação. Desta forma, temos um modelo de curto prazo onde os fatores econômicos, institucionais, e sociais determinam a condução administrativa municipal.

No âmbito municipal, a disponibilidade e a qualidade das variáveis representativas destes fatores impõem uma grande restrição aos modelos empíricos. Ainda assim, procurou-se indicadores, que pudessem cobrir diferentes aspectos dos incentivos ao cometimento de irregularidades tais como o volume de recursos recebidos, o fundo de participação municipal, o grau de desenvolvimento municipal, o controle social, e outros aspectos institucionais como o segundo mandato do prefeito e sua filiação partidária. Estes e outros fatores são detalhados abaixo.

\subsection{Volume de recursos federais transferidos e fiscalizados pela CGU e o Fundo de Participação dos Municípios}

A expectativa é de que a variável de recursos federais transferidos e fiscalizados retrate o grau de dependência dos entes municipais a esse tipo de recursos, visto que o seu valor médio é muito próximo do valor médio dos recursos transferidos por meio do Fundo de Participação Municipal, considerando os municípios fiscalizados, ver tabela 1, em que esses últimos, para a maioria dos municípios pequenos e médios, são a principal fonte tributária. Vale salientar que nos estados do Norte/Nordeste, a relação recursos fiscalizados/despesa orçamentária ficou entre $21 \%$ a $51 \%$, em que pese nos estados do Sudeste/Sul ter ficado entre 5\% e 11\%, (ver CAMPOS, 2012).

A dependência pode gerar oportunidades para adoção de atos de corrupção, inclusive atividades rent-seeking ${ }^{9}$, visto que o município não tem

9 As atividades rent-seeking se estendem a um contexto de corrupção política e governamental, envolvendo partidos políticos, funcionários de alto escalão, governo, empresários e lobistas, podendo ter como fundamento o financiamento de campanha eleitoral legal ou irregular 
uma estrutura de governança permanente para o gerenciamento dos recursos recebidos para financiar programas não sustentados somente por suas receitas próprias. Ainda por tratarem-se de receitas excepcionais, os atos irregulares decorrentes podem ser menos perceptíveis à população, que enxerga primordialmente a execução das receitas orçamentárias municipais permanentes como do fundo de participação dos municípios e quotas do ICMS e IPVA (BROLLO et al. 2013; IVANYANA e SHAR ,2010; FERRAZ e FINAN, 2011).

Os dados dessa variável foram obtidos diretamente dos relatórios de fiscalização da CGU, que trazem o volume de recursos transferidos por programa e os valores fiscalizados. É esperado que um maior volume de recursos leve a um maior número de irregularidades cometidas. Esta relação, no entanto, poderia ser menos óbvia se a percepção de risco de ser flagrado por autoridades fiscais fosse proporcional ao montante de recursos recebidos. Como os municípios, neste caso, são sorteados aleatoriamente, este risco é distribuído igualmente entre os mesmos, gerando um efeito montante para esta variável. Vale destacar que um dos principais objetivos deste trabalho é medir esta elasticidade das irregularidades com respeito ao volume dos recursos recebidos, controlando ainda por outros cofatores.

Como variável de controle, foi inserido também no modelo o Fundo de Participação dos Municípios (FPM), que se trata de um mecanismo do federalismo fiscal com vista a repartir receitas fiscais cujas competências constitucionais de arrecadação são do governo federal. A introdução dessa variável foi no sentido de verificar se a fonte de recurso impacta o comportamento ilícito do gestor municipal na execução de uma despesa pública.

O FPM Equivale a $23,5 \%$ dos impostos de renda e de produtos industrializados (Emenda Constitucional 55/2007) ${ }^{10}$. O município executa os recursos do FPM de acordo com o seu orçamento aprovado pela Câmara de Vereadores, mas há uma parte do FPM que é vinculada ao FUNDEB, 20\%, e aos gastos com o Sistema Único de Saúde, 15\%.

e/ou o beneficiamento direto dos agentes públicos.

10 Para fins de distribuição do FPM, os municípios são distribuídos em três classes: capital $(10 \%)$, interior $(86,4 \%)$ e reserva $(3,6 \%)$. Em cada classe são utilizados os fatores de população (diretamente proporcional) e de renda per capita (inversamente proporcional), para o efetivo cálculo do coeficiente de cada município, exceto no caso dos municípios do interior, em que ao invés da renda per capita é usado o tamanho máximo e mínimo da população. Esse cálculo é feito pelo Tribunal de Contas da União, a partir dos dados obtidos pelo IBGE. (ver:http://www.tesouro.gov.br/estados_municipios/transferencias_constitucionais.asp). 
Espera-se, a priori, que essa variável, em termos de direção, comporte-se de forma semelhante à variável relativa aos recursos fiscalizados; ou seja, quanto maior o FPM maior o número de irregularidades, tendo em vista as oportunidades de desvio que são abertas à luz das fragilidades institucionais das prefeituras. Contudo, espera-se, também, que os efeitos sejam menores pelo fato de não serem recursos excepcionais e serem de conhecimento mais amplo dos munícipes.

\subsection{IFDM (Índice Firjan de Desenvolvimento Municipal) ${ }^{11}$}

O índice capta a renda per capita, a escolaridade e a estrutura de saneamento e saúde da região. O IFDM varia de 0 a 1 e quanto maior, mais desenvolvido é o município. A variável IFDM irá captar, também, os efeitos da qualidade das instituições, que, normalmente, são boas em regiões de IFDM elevado. Brunetti e Weder (2003) encontraram que menos corrupção está correlacionada a melhor estrutura burocrática e a um poder judiciário mais efetivo.

Por isso, espera-se que quanto maior o IFDM menor a probabilidade de corrupção municipal. Alguns estudos cross country, com base em Índices de Corrupção, mostram que países pobres ou em desenvolvimento e que possuem estrutura de governança frágil e fuga de capital são mais corruptos (MAURO, 1995; TANZI, 1998; KAUFMANN et al., 2003; NEEMAN et al., 2003 entre outros).

Cabe salientar que nesse tipo de modelo microeconométrico, o qual se preocupa com as tomadas de decisão dos gestores municipais no gerenciamento dos recursos transferidos no curto prazo, a variável IFDM expressa uma situação institucional já encontrada, e difícil de ser revertida no curto prazo.

\subsection{Densidade Populacional}

Intuitivamente, pode-se, a priori, esperar um efeito negativo desta variável na corrupção, pois onde há dispersão, como nos municípios de baixa 11 Calculado e divulgado pela Federação das Indústrias do Rio de Janeiro. www.imprensa@ firjan.org.br. 
densidade demográfica, torna-se mais propício o ambiente para as práticas administrativas ilícitas, haja vista a dificuldade de controle por parte do próprio governo e da população. Por outro lado, poder-se-ia esperar um sinal positivo, o que seguiria a lógica da ação coletiva, teorizada por Olson (1965), a qual foca os benefícios concentrados versus custos difusos nas ações coletivas ${ }^{12}$. Afirma-se que, a menos que o número de indivíduos de um grupo seja muito pequeno, ou ao menos que haja coerção ou algum outro dispositivo especial para fazer as pessoas agirem em seu interesse comum, os indivíduos racionais e auto interessados não agirão para atingir seus interesses comuns ou do grupo. Com isso, é plausível esperar que munícipios de alta densidade demográfica tenham mais grupos organizados e mais indivíduos atuando na forma de rent-seeking.

\subsection{Contágio de Fronteira}

Consiste de uma variável tipo dummy com valor 1 no caso do município fronteiriço a outro considerado corrupto, e 0 de outra forma. Esta variável busca identificar se há transferência de prática de corrupção ou se é área de dominância de grupos. Reflete o contágio de um município para outro, que pode ocorrer por meio de influências decorrentes de famílias, de empresas de fornecedores de bens e serviços e de escritório de contabilidade que atuam em municípios vizinhos.

Variável dessa natureza foi usada por Karahan et al. (2006), e espera-se um efeito positivo, que pode refletir não apenas um efeito de indução entre prefeitos facilitado por transferência tecnológica ou informativa, como também um reforço à percepção do risco de ser pego por autoridades de controle fiscal.

A classificação do município vizinho como corrupto ou não foi realizada com base em Campos (2012), que, considerando a forte correlação entre os tipos de irregularidades, usou o somatório das irregularidades graves e médias de cada município e comparou a uma média das irregularidades ponderada pelo volume de recursos fiscalizado, resultando em um ponto de corte que definia o município de tendência à corrupção ou município

12 A ideia de se promoverem quaisquer manifestações grupais é precedida de cálculos racionalmente elaborados com o intuito de vislumbrar os possíveis ganhos e benefícios que o ato pode proporcionar. 
sem tendência à corrupção de acordo com o somatório das irregularidades obtido por cada município. A partir dessa classificação, seguimos o método de Karahan et al. (2006), ou seja, verificamos a localização de cada município e suas vizinhanças ${ }^{13}$.

\subsection{Variáveis Políticas: Reeleição do Prefeito Municipal e Filiação Partidária do Prefeito.}

A possibilidade de reeleição pode fazer com que os prefeitos gastem de forma eficiente os recursos recebidos. Assim, se o prefeito que realizou o gasto não concorre mais, espera-se uma atitude de gasto menos eficiente, havendo extração de renda indevida por ele ao longo do seu segundo mandato. Empiricamente, não há um consenso sobre o sinal do coeficiente, em que pese Ferraz e Finan (2011) terem encontrado que a corrupção municipal é maior no segundo mandato. Especificamente, será uma variável representada por uma dummy, onde1 (um) expressa prefeito em seu segundo mandado consecutivo e 0 (zero) prefeito em primeiro mandato.

Foram trabalhadas, ainda, duas variáveis dummies de política, no sentido de verificar os efeitos que tem o partido do prefeito em relação ao do presidente da república e com relação ao do governador sobre a tendência de corrupção municipal. Supõe-se que pertencer a mesma sigla partidária do presidente/governador possibilita facilidades quanto à condução dos recursos transferidos e ao controle realizado pelo ministério/secretaria supervisor das transferências, ou seja, haveria uma estrutura institucionalizada de favorecimento no âmbito das esferas governamentais, inclusive quanto aos encargos decorrentes dos financiamentos privado das eleições.

\subsection{Controle Social}

Essa variável está relacionada ao nível de transparência do município, o que envolve também as questões de prestação de contas dos recursos gas-

13 Número de corte = somatório ( $\left(\right.$ recursos fiscalizados* $\left(n^{\circ}\right.$ de Falhas graves $+\left(n^{\circ}\right.$ de falhas médias/4)))/somatório dos recursos fiscalizados. Vale ressaltar que existe a possibilidade de um município não ter vizinhança corrupta pelo fato dos municípios vizinhos não terem sido sorteados, o que impossibilita a elaboração de uma matriz espacial para fins de verificar as interações espaciais (cross unit). 
tos e dos resultados. Quanto maior a transparência menor é a corrupção (KLITIGAARD, 1994; AVELINO et al., 2013). Por isso, espera-se que a presença de um controle social atuante reduza a corrupção municipal. Essa variável será obtida a partir da leitura dos relatórios de fiscalização municipal, realizada pela CGU, em que o auditor examina a atuação dos conselhos municipais (por exemplo: Conselho de Alimentação Escolar, Conselho do FUNDEF, Conselho Municipal de Saúde, entre outros) quanto à sua existência, a sua composição e à realização de reuniões e registros de atas.

Considerou-se controle social atuante quando não havia registro nos relatórios de fiscalização concernentes a problemas na atuação dos conselhos, inclusive na sua formação. Também esta variável é representada como uma dummy, que assume o valor de 1 (um) no caso de controle social atuante, caso contrário, assume valor 0 (zero).

Cabe salientar que a qualificação do controle social por parte da CGU ocorre desvinculada de tempo e de orientação de qualquer processo de averiguação das irregularidades das transferências dado que os conselhos municipais dos programas são previstos em leis e normas específicas e independentes. A motivação para a previsão da criação dos conselhos tem como premissa o envolvimento da população no planejamento, organização e controle das ações do programa no âmbito municipal, que sobrepuja a existência de irregularidades formalmente levantadas e publicadas por qualquer entidade de controle fiscal.

\section{Modelos econométricos}

\section{Modelos de Contagem}

A variáveis dependentes de interesse neste trabalho são o número de irregularidades do tipo média e grave encontradas em cada município investigado pela CGU por meio do programa de fiscalizações deste órgão. Como estas são variáveis inteiras (discretas) não-negativas os modelos de contagem acomodam melhor este tipo de distribuição do que modelos lineares tradicionais (CAMERON e TRIVEDI, 2009). Salienta-se que Albuquerque; Ramos (2006) e Ferraz; Finam (2011) também usaram variáveis de contagem para trabalhar esse tipo de irregularidade como variável dependente. 
As especificações dos modelos de contagem variam de acordo com pressupostos testáveis assumidos, entre outros destacam-se a evidência ou não de sobredispersão, e o viés de baixa para a média motivado por excessos de zeros observados (LONG; FREESE, 2003).

O modelo de regressão de Poisson (MRP) é a referência inicial para modelos de contagem. O mesmo é derivado da distribuição de Poisson que é dada por:

$$
\operatorname{Pr}(y \mid \mu)=\frac{e^{-\mu} \mu^{y}}{y !}
$$

onde y é a variável de contagem. A heterogeneidade observada por indivíduo é incluída no modelo assumindo uma média condicional de $\mu_{i}$ como uma função exponencial das variáveis explicativas $x_{i}$.

$$
\mu_{i}=E\left(y_{i} \mid x_{i}\right)=e^{\left(x_{i} \beta\right)}
$$

Um pressuposto forte do MRP é a equidispersão, a qual normalmente não ocorre em dados empíricos. A alternativa à sobredispersão é assumida no modelo de regressão negativo binomial que adiciona um parâmetro de heterogeneidade não observada $\left(\varepsilon_{i}\right)$ por indivíduo.

$$
\mu_{i}=E\left(y_{i} \mid x_{i}\right)=e^{\left(x_{i} \beta+\varepsilon_{i}\right)}=e^{\left(x_{i} \beta\right)} e^{\varepsilon_{i}}=e^{\left(x_{i} \beta\right)} \delta_{i}
$$

sendo $\delta_{i}=e \varepsilon_{i}$. $\bigcirc$ modelo é identificado assumindo que $\delta$ tem uma distribuição gama e possui média igual a $1(E(\delta)=1))^{14}$. Desta forma, a função de distribuição condicionada negativa binomial é dada por:

$$
\operatorname{Pr}(y \mid x)=\frac{\Gamma\left(y+\alpha^{-1}\right)}{y ! \Gamma\left(\alpha^{-1}\right)}\left(\frac{\alpha^{-1}}{\alpha^{-1}+\mu}\right)^{\alpha^{-1}}\left(\frac{\mu}{\alpha^{-1}+\mu}\right)^{y}
$$

Nesta distribuição, $\Gamma$ é a função gama, e $\alpha$ é o parâmetro que determina o grau de dispersão dos valores previstos, e que torna os modelos Poisson e Negativo Binomial aninhados, dado que os mesmos coincidem quando este parâmetro torna-se zero. Observa-se por (2) e (3) que os modelos possuem o mesmo valor esperado para a média condicional, mas a variância 
do modelo negativo binomial difere e é dada por ${ }^{15}$ :

$$
\operatorname{Var}\left(y_{i} \mid x\right)=\mu_{i}+\alpha \mu_{i}^{2}
$$

Pode-se então testar a hipótese de sobredispersão, contrastando os modelos pela significância estatística ${ }^{16}$ de $\alpha$.

Outro problema empírico normalmente existente em dados de contagem, que tornam fracas as previsões para os modelos citados, é o excessivo número de zeros encontrados para algumas variáveis ${ }^{17}$. Neste estudo de caso, o cometimento de delito grave por parte dos administradores municipais é fator de risco que pode comprometer o "capital político" dos mesmos. Embora a percepção comum seja que este risco seria baixo, evidenciou-se na base de dados do CGU que $52 \%$ dos municípios analisados não apresentaram este tipo de irregularidade. Desta forma, modelos alternativos de contagem que considerem esta evidência podem gerar um melhor ajuste para o mesmo.

Os modelos de contagem com zero inflado (MCZI) introduzidos por Lambert (1992) ajustam os modelos tradicionais introduzindo um componente que aumenta a probabilidade de se encontrar zeros na amostra. Se este componente for definido por $\pi$, por exemplo, então o modelo é especificado como:

$$
\operatorname{Pr}(y=j)=\left\{\begin{array}{l}
\pi+(1-\pi) f_{2}(0), \text { se } j=0 \\
(1-\pi) f_{2}(j), \text { se } j>0
\end{array}\right.
$$

onde $f_{2}$ é a distribuição de contagem tradicional (Poisson ou Binomial), e a probabilidade $\pi$ pode ser uma constante, ou mais tradicionalmente, pode depender de variáveis explicativas via modelos binários como logit ou probit. Neste caso de modelo misto, os parâmetros tanto para o modelo de probabilidade de zero $\left(\pi=\pi\left(x_{1}, \beta_{1}\right)\right)$ como do modelo de contagem $\left(f_{2}\left(y \mid x_{2}, \beta_{2}\right)\right)$, são estimados em conjunto por máxima verossimilhança.

15 Essa a maneira mais tradicional de assumir a forma funcional da sobredispersão, que ficou conhecida como NB2 (CAMERON; TRIVEDI, 2005).

16 Vale destacar que como $\alpha$ deve ser maior ou igual a zero é necessário ajustar o nível de significância do teste pois sua distribuição assintótica é apenas metade de uma distribuição normal. Como os modelos MRP e NB2 são aninhados é possível também contrastá-los utilizando o diferencial de suas funções de verossimilhança com um teste de qui-quadrado $\left(G^{2}=2\left(\ln L_{N B 2}-\ln L_{P R M}\right)\right)$.

17 Como exemplo de variáveis com excessos de zeros podemos citar número de internações hospitalares anuais por indivíduo, acidentes de trânsito, peças defeituosas, entre outras. 
A comparação entre modelos inflados ou não pode ser feita pela capacidade de ajuste dos mesmos através das probabilidades estimadas para as médias, por critérios de informações (AIC ou BIC), ou pelo teste de Vuong no caso de modelos não-aninhados ${ }^{18}$. Long e Freese (2003) sugerem o uso conjunto destes critérios o que será utilizado neste trabalho.

\section{Base de dados}

De 2003 a 2010 foram realizados 30 sorteios no Programa de Fiscalizações da CGU que geraram 1822 relatórios de fiscalização para os municípios brasileiros. Destes, foram selecionados 1.600 para compor a base de dados, ver anexo 1, pois foi descartada a segunda fiscalização para aqueles municípios que foram sorteados duas vezes e desconsiderados os municípios para os quais não existiam informações disponíveis para todas as variáveis. Por se tratarem de municípios com menos de 500 mil habitantes, as características médias dos mesmos revelam um conjunto populacional ainda mais vulnerável à existência de irregularidades administrativas, onde os custos de oportunidade dos recursos públicos são ainda maiores. A Tabela 1 abaixo mostra o formato numérico das variáveis sugeridas como determinantes da corrupção, bem como algumas estatísticas descritivas como média e desvio padrão. Observa-se que na média os municípios possuem um nível de desenvolvimento comparativamente baixo ${ }^{19}$, e com uma atuação de fiscalização pouco incisiva. Neste último aspecto verifica-se que somente $14,3 \%$ dos municípios investigados mostraram ter conselhos sociais atuantes.

Por se tratarem de municípios médios e pequenos o volume médio de transferências voluntárias e legais ${ }^{20}$ (no caso do Fundef/Fundeb para alguns municípios, que precisam de complementação da União para o atingimento do piso per capita) fica próximo dos $\mathrm{R} \$ 7$ milhões, mas com uma variância considerável em torno desta média. Este valor médio é considerável, visto que ele se encontra muito próximo da média das transferên-

18 Detalhes específicos para estes testes podem ser vistos em Long; Freese (2003).

19 Enquanto o Índice Firjam médio para o país em 2010 foi de 0,719 o índice médio para os municípios da amostra foi de 0,5953 .

20 Este caso se aplica aos recursos do Fundef/Fundeb para alguns municípios, que precisam de complementação da União para o atingimento do piso per capita, na forma da legislação. 
cias via FPM. A grande amplitude de valores recebidos pelos municípios também garante uma análise de elasticidade mais robusta com relação a esta variável.

Tabela 1 Definição e Estatísticas Descritivas das Variáveis Explicativas

\begin{tabular}{|c|c|c|c|}
\hline Variável & $\begin{array}{l}\text { Definição/ } \\
\text { Fonte }\end{array}$ & Média & $\begin{array}{l}\text { Desvio } \\
\text { Padrão }\end{array}$ \\
\hline Controle Social & $\begin{array}{l}\text { Variável dummy com valores iguais a } 1 \text { se } 0 \\
\text { conselho social é atuante, e } 0 \text { caso contrário. } \\
\text { Fonte: CGU/Relatórios de Fiscalização }\end{array}$ & 0,1435 & 0,3507 \\
\hline $\begin{array}{l}\text { Valor } \\
\text { Fiscalizado }\end{array}$ & $\begin{array}{l}\text { Valor fiscalizado total das transferências para } \\
\text { os municípios em R\$ milhões (a preços de 2010). } \\
\text { Fonte: CGU/Relatório de Fiscalizações }\end{array}$ & 7,081 & 12,263 \\
\hline IFDM & $\begin{array}{l}\text { Índice Firjam de Desenvolvimento Municipal. } \\
\text { Fonte: www.firjan.org.br/ifdm }\end{array}$ & 0,5953 & 0,1118 \\
\hline $\begin{array}{l}\text { Vizinhança } \\
\text { Corrupta }\end{array}$ & $\begin{array}{l}\text { Variável dummy com valores iguais a } 1 \text { se o muni- } \\
\text { cípio avaliado fizer fronteira com um município } \\
\text { já avaliado como corrupto (irregularidades acima } \\
\text { da média), e } 0 \text { caso contrário. } \\
\text { Fonte: CGU/Relatórios de Fiscalização }\end{array}$ & 0,6060 & 0,4887 \\
\hline $\begin{array}{l}\text { Densidade } \\
\text { Demográfica }\end{array}$ & $\begin{array}{l}\text { População do município em centenas dividido } \\
\text { pela área em Km2 do município. } \\
\text { Fonte: IBGE. }\end{array}$ & 0,9607 & 5,4777 \\
\hline $\begin{array}{l}\text { Reeleição de } \\
\text { Prefeito }\end{array}$ & $\begin{array}{l}\text { Variável dummy com valores iguais a } 1 \text { se o prefei- } \\
\text { to do período fiscalizado vier de uma reeleição, } \\
\text { e } 0 \text { caso contrário. } \\
\text { Fonte: Tribunais Regionais Eleitorais. }\end{array}$ & 0,3401 & 0,4738 \\
\hline $\begin{array}{l}\text { Partido do } \\
\text { Prefeito com relação } \\
\text { ao presidente da } \\
\text { república }\end{array}$ & $\begin{array}{l}\text { Variável dummy com valores iguais a } 1 \text { se } 0 \\
\text { partido do prefeito for o mesmo do presidente } \\
\text { da república e } 0 \text { caso contrário. } \\
\text { Fonte: Tribunais Regionais Eleitorais. }\end{array}$ & 0,05627 & 0,2305 \\
\hline $\begin{array}{l}\text { Partido do } \\
\text { Prefeito com relação } \\
\text { ao governador do } \\
\text { estado }\end{array}$ & $\begin{array}{l}\text { Variável dummy com valores iguais a } 1 \text { se o parti- } \\
\text { do do prefeito for o mesmo do governador do seu } \\
\text { estado e } 0 \text { caso contrário. } \\
\text { Fonte: Tribunais Regionais Eleitorais. }\end{array}$ & 0,2244 & 0,4173 \\
\hline $\begin{array}{l}\text { Fundo de Participação } \\
\text { do Município }\end{array}$ & $\begin{array}{l}\text { Valor do FPM em R\$ milhões (a preços de 2010). } \\
\text { Fonte FINBRA/STN/MF }\end{array}$ & 7,184 & 7,254 \\
\hline
\end{tabular}

Fonte: Elaboração própria.

fato de que $60 \%$ dos municípios vizinhos apresentam um alto índice de irregularidades já sugere uma espécie de endemia do comportamento 
irregular, o que pode ser constatado na Tabela 2 abaixo. Apenas 1,17\% dos municípios não apresentou irregularidades do tipo média, reforçando a suspeição comum da sociedade quanto à prática de corrupção pelos políticos. No entanto, este índice é bem maior quando se trata de irregularidades graves $(52,71 \%)$. $O$ diferencial na distribuição destes dois tipos de irregularidades fica evidente quando são analisadas as dispersões das mesmas (Figura 1 e 2 ) entre os municípios.

Tabela 2 Distribuição das Irregularidades por Tipo entre os Municípios

\begin{tabular}{l|r|r|r|r}
\hline \multirow{2}{*}{$\begin{array}{l}\text { Número de } \\
\text { irregularidades }\end{array}$} & $\mathbf{N}$ & $\mathbf{T}$ & $\mathbf{N}$ & Tipo Médias \\
\cline { 2 - 6 } & 19 & 1,17 & 855 & 52,71 \\
\hline $\mathbf{0}$ & 192 & 11,85 & 219 & 13,51 \\
\hline $\mathbf{1 - 2}$ & 494 & 30,47 & 242 & 14,92 \\
\hline $\mathbf{3 - 4}$ & 254 & 15,67 & 273 & 16,83 \\
\hline $\mathbf{5 - 1 0}$ & 681 & 40,84 & 33 & 2,03 \\
\hline $\mathbf{1 1 - \text { ou mais }}$ & 1621 & & 1622 & \\
\hline Total & 9,92 & & 2,08 & \\
\hline Médias & & &
\end{tabular}

Fonte: Elaboração própria.

O fato das distribuições descritivas das variáveis de irregularidades possuírem formatos diferentes reforça o uso de modelagens de contagem adequadas a cada variável. No caso das irregularidades médias utilizou-se o modelo negativo binomial (MNB), enquanto que para as irregularidades graves utilizou-se o modelo negativo binomial com zeros inflados (MNBZI).

Figura 1 Distribuição das Irregularidades Médias por Municípios

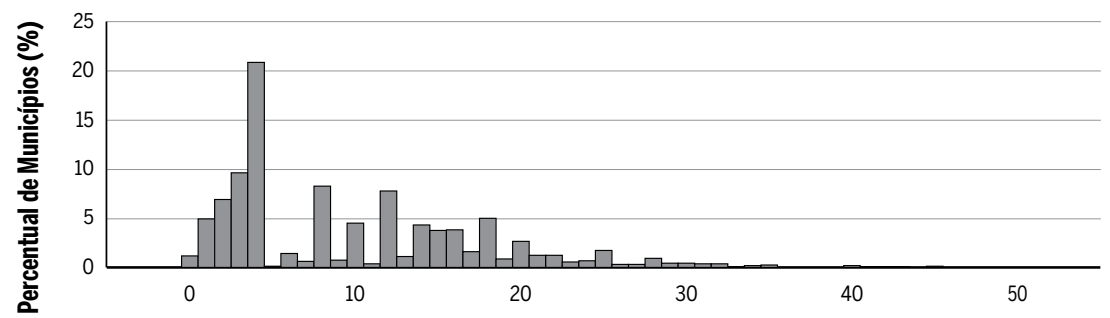

Número de Irregularidades Médias 
Figura 2 Distribuição das Irregularidades Graves por Municípios

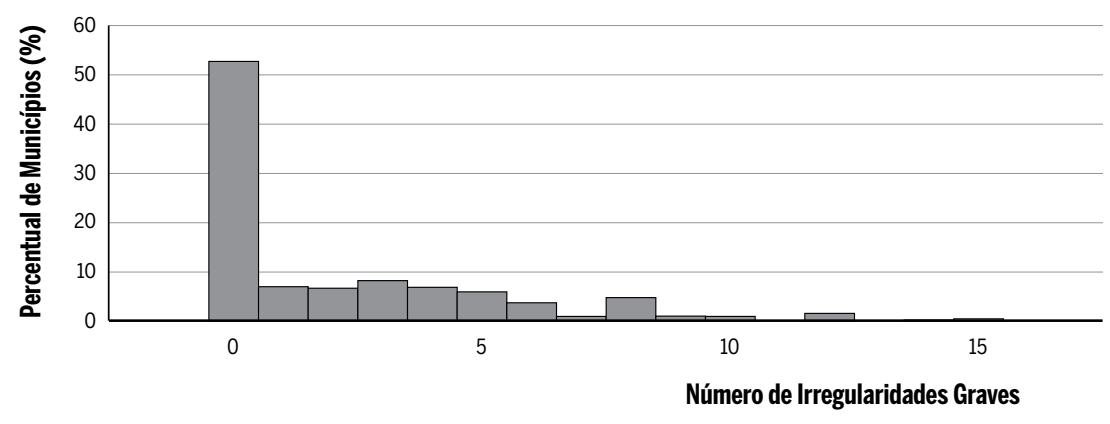

\section{Resultados}

Inicialmente, serão comentados os resultados relativos às irregularidades médias, sendo, posteriormente, analisados os resultados referentes às irregularidades graves.

Os testes para presença de sobredispersão mais os indicadores de ajustes dos modelos (AIC e BIC) levaram à escolha do modelo negativo binomial vis-à-vis o modelo tradicional de Poisson, embora os resultados dos mesmos não tenham sido qualitativamente diferentes para as irregularidades do tipo média como se percebe na Tabela $3^{21}$.

Os resultados mostram que o fato do prefeito estar em segundo mandato ou estar no mesmo partido do presidente ou do governador, parecem não ter influência significante no número de irregularidades médias. O efeito da variável segundo mandato não se alinha aos resultados encontrados por Ferraz e Finan (2011) e a Albuquerque e Ramos(2006), os quais, utilizando outras estruturas metodológicas ${ }^{22}$, encontraram efeitos positivos da reeleição nas irregularidades. Tal divergência nos resultados pode ser explicada pelo fato de considerarmos apenas as irregularidades médias, visto que os outros pesquisadores não separaram por tipo de irregularidade para fins de estimação.

21 A hipótese de sobredispersão foi testada pela razão de verossimilhança dos modelos, favorecendo o modelo binomial. Como o número de zeros para irregularidades médias é muito pequeno os modelos com zero inflados para esta variável foram descartados.

22 Os autores utilizaram análise de regressão descontínua e uma variável dependente contínua para medir as irregularidades municipais. 
No caso do partido político do prefeito com relação ao do presidente e ao governador, é plausível afirmar que o tipo de irregularidade média não está sendo influenciado por algum privilégio escuso, como o tratamento diferenciado no controle ministerial dos recursos transferidos para os munícipios do mesmo partido.

Outros resultados foram de acordo com as expectativas definidas na seção 3 desse artigo. Por exemplo, um controle social atuante no município gera uma tendência menor de se encontrar irregularidades do tipo média nos relatórios de fiscalização da CGU. O mesmo raciocínio vale para o indicador de desenvolvimento municipal, que apresentou sinal negativo para o coeficiente e um efeito marginal da ordem de -21,37, levando a uma elasticidade de $-1,39^{23}$. Assim, uma melhoria do indicador em $10 \%$ está associada a uma redução dos achados médios em 13,90\%, o que é um efeito significativo.

Em conjunto, o desenvolvimento econômico e social, quando acompanhado do desenvolvimento institucional de instrumentos de controle social, produzem um efeito ampliado na redução das ingerências no uso dos recursos públicos.

Por outro lado, quando o desenvolvimento ocorre com grande adensamento populacional o efeito parece ser propício ao aumento da tendência de corrupção municipal. Este efeito, possivelmente, decorre da influência de grupos com comportamentos rent-seeking, que são em maior número e melhor organizados em cidades de população mais concentrada ${ }^{24}$.

Também foi verificado um efeito contágio em que o comportamento corrupto nos municípios vizinhos estimula o ato ilícito no município de referência. Para um município com características médias, o número de irregularidades médias encontradas aumenta em 1,77 quando o mesmo está margeado por um município com várias irregularidades. A própria propagação do ato ilícito ou a percepção da falta de punição nos vizinhos em um contexto de inércia do comportamento corrupto favorecem este resultado. Por outro lado, este resultado mostra que a ação fiscal, quando

23 Calculada a partir das médias das variáveis, por meio de (dy/dx)(x/y), em que (dy/dx/) é o efeito marginal.

24 Acemoglu et al. (2000) enfatizam que diferentes grupos e indivíduos se beneficiam de diferentes instituições econômicas e existe, geralmente, um conflito sobre essas escolhas sociais, ultimamente resolvido em favor dos grupos com maior poder político. De acordo, com Olson (1965), os grupos de interesse não agem em busca de benefícios comuns para a sociedade, pois atuam disputando recursos limitados. 
efetivada e consubstanciada nas ações punitivas, podem levar a um efeito externalidade na redução das irregularidades municipais.

Com relação ao valor fiscalizado, seu efeito positivo era esperado pela própria possibilidade de incidência. Quanto maior o valor recebido pelo município maior a probabilidade do aumento do número de irregularidades encontradas. Ou seja, quanto maior for a oportunidade de cometer desvios de conduta, mais eles aparecerão.

Tabela 3 Modelos de Contagem para Achados de Irregularidades Médias

\begin{tabular}{|c|c|c|c|c|}
\hline \multirow[t]{2}{*}{ Variável } & \multicolumn{2}{|r|}{ Modelo Poisson } & \multicolumn{2}{|c|}{ Modelo Negativo Binomial } \\
\hline & Coeficiente & Efeito Marginal & Coeficiente & Efeito Marginal \\
\hline Controle Social & $\begin{array}{l}-0,1513 \\
(-6,08)\end{array}$ & $\begin{array}{l}-1,325 \\
(-6,42)\end{array}$ & $\begin{array}{r}-0,1688 \\
(-3,23)\end{array}$ & $\begin{array}{l}-1,4582 \\
(-3,43)\end{array}$ \\
\hline $\begin{array}{l}\text { Valor Fiscalizado } \\
\text { (em R\$ milhões) }\end{array}$ & $\begin{array}{r}0,01081 \\
(15,66)\end{array}$ & $\begin{array}{r}0,099 \\
(15,66)\end{array}$ & $\begin{array}{l}0,0172 \\
(6,92)\end{array}$ & $\begin{array}{l}0,1586 \\
(6,89)\end{array}$ \\
\hline $\begin{array}{l}\text { FPM } \\
\text { (Em R\$ milhões) }\end{array}$ & $\begin{array}{r}0,0087 \\
(6,19)\end{array}$ & $\begin{array}{l}0,080 \\
(6,19)\end{array}$ & $\begin{array}{r}0,0078 \\
(1,92)\end{array}$ & $\begin{array}{r}0,0722 \\
(1,92)\end{array}$ \\
\hline IFDM & $\begin{array}{l}-2,4099 \\
(-29,91)\end{array}$ & $\begin{array}{l}-22,253 \\
(-30,81)\end{array}$ & $\begin{array}{l}-2,3341 \\
(-12,94)\end{array}$ & $\begin{array}{r}-21,3780 \\
(-12,76)\end{array}$ \\
\hline Vizinhança Corrupta & $\begin{array}{l}0,1997 \\
(11,16)\end{array}$ & $\begin{array}{r}1,807 \\
(11,43)\end{array}$ & $\begin{array}{l}0,1971 \\
(5,15)\end{array}$ & $\begin{array}{l}1,7703 \\
(5,23)\end{array}$ \\
\hline Densidade Demográfica & $\begin{array}{r}0,0025 \\
(2,01)\end{array}$ & $\begin{array}{r}0,011 \\
(2,01)\end{array}$ & $\begin{array}{r}0,0041 \\
(1,22)\end{array}$ & $\begin{array}{r}0,0377 \\
(1,22)\end{array}$ \\
\hline Reeleição de Prefeito & $\begin{array}{r}0,0260 \\
(1,56)\end{array}$ & $\begin{array}{r}0,241 \\
(1,55)\end{array}$ & $\begin{array}{r}0,0185 \\
(0,49)\end{array}$ & $\begin{array}{l}0,1701 \\
(0,49)\end{array}$ \\
\hline Partido Presidente & $\begin{array}{r}-0,1550 \\
(-4,26)\end{array}$ & $\begin{array}{l}-1,337 \\
(-4,57)\end{array}$ & $\begin{array}{r}-0,1048 \\
(-1,34)\end{array}$ & $\begin{array}{r}-0,9169 \\
(-1,40)\end{array}$ \\
\hline Partido Governador & $\begin{array}{r}0,3069 \\
(1,61)\end{array}$ & $\begin{array}{l}0,030 \\
(1,61)\end{array}$ & $\begin{array}{r}0,0288 \\
(0,68)\end{array}$ & $\begin{array}{r}0,2659 \\
(0,68)\end{array}$ \\
\hline Constante & $\begin{array}{l}3.4097 \\
(69,47)\end{array}$ & & & \\
\hline Ln (alpha) & & & & $\begin{array}{l}-0,9342 \\
(-20,52)\end{array}$ \\
\hline alpha & & & & 0.3928 \\
\hline AIC & & 13350,866 & & 10129,811 \\
\hline BIC & & 13404,706 & & 10189,035 \\
\hline $\mathrm{N}$ & & 1600 & & 1600 \\
\hline
\end{tabular}

Fonte: Elaboração própria. Valores z entre parênteses. 
Assim, considerando o efeito marginal correspondente à variável "valor fiscalizado", Tabela 3, em média, espera-se encontrar uma irregularidade do tipo média a cada $\mathrm{R} \$ 6,3$ milhões recebidos. Ademais, utilizando-se, ainda, o efeito marginal, estima-se uma elasticidade pontual de 0,113 . Assim, um aumento de $10 \%$ no volume de recursos transferidos para o $\mathrm{mu}-$ nicípio está associado a um aumento de 1,13\% nos achados tipos médios.

Com relação aos recursos do FPM recebidos pelos municípios, a direção é semelhante a dos recursos de transferências federais de programa sociais e de emendas parlamentares, ou seja, quanto maior o valor do FPM pelo município maior deverá ser o número de irregularidades encontradas, mas, comparativamente, os efeitos marginais são menores, conforme se verifica na tabela 3. Aliás, o resultado quanto à direção se alinha ao fato que em muitos programas sociais há recursos tanto das transferências federais voluntárias como de FPM, como contrapartida. Assim, quanto maior for a oportunidade de se cometer desvios de conduta pelos gestores municipais, mais irregularidades aparecerão, em que pesem não serem na mesma magnitude. Tal fato é reforçado pela supressão do FPM do modelo e mesmo assim os resultados das variáveis quanto à direção e significância estatística se mantêm.

\section{Gráfico 1 Erros em Modelos de Contagem para Irregularidades Grave Testes dos Modelos de Contagem para Irregularidades Graves}

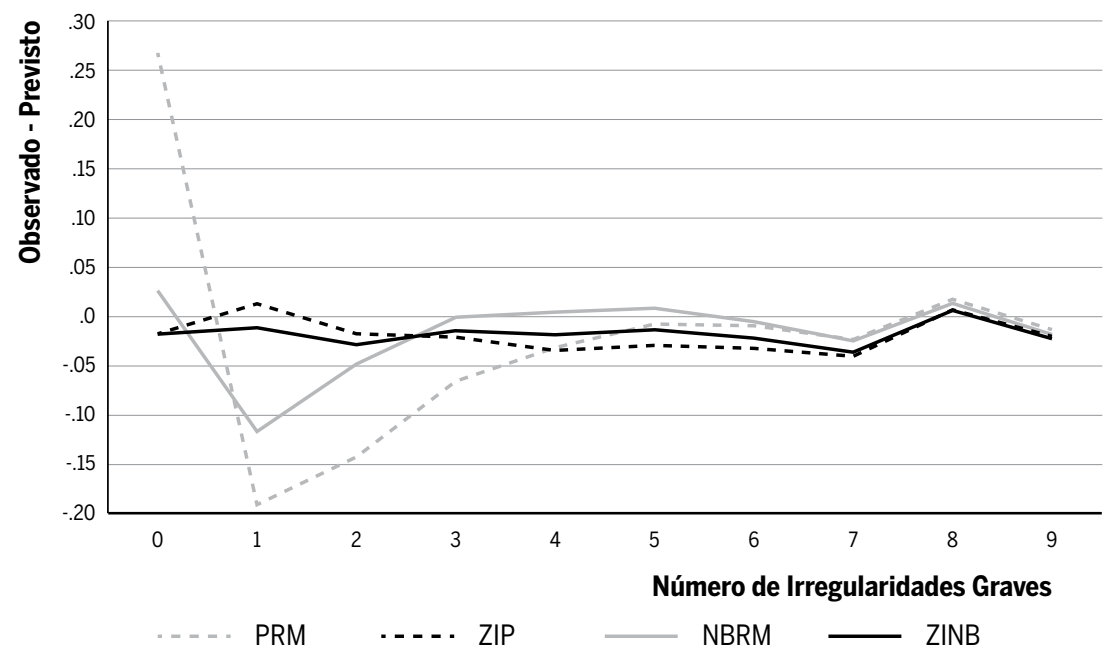


Para o modelo de achados graves foi necessário primeiro definir o modelo de contagem mais ajustado aos dados dos relatórios da CGU. Como o percentual de zeros é bem alto para este tipo de achado, foi preciso considerar modelos de zero inflado nesta comparação. Utilizando tanto critérios de previsão, Gráfico 1, quanto de ajustes, foram utilizados e comparados vários critérios de informação (AIC e BIC), e o teste de Vuong para modelos não-aninhados, ver Quadro 02. Com base nesses testes, o modelo binomial com zero inflado foi escolhido.

Quadro 2 Testes de Ajustes em Modelos de Contagem para Irregularidades Graves

\begin{tabular}{|c|c|c|c|c|c|c|c|}
\hline PRM & $B I C=$ & 7520.599 & $A I C=$ & 7466.815 & Preferido & Sobre & Evidência \\
\hline \multirow[t]{3}{*}{ vs NBRM } & $\mathrm{BIC}=$ & 5747.522 & Dif $=$ & 1772.077 & NBRM & PRM & \multirow[t]{3}{*}{ Muito Forte } \\
\hline & $\mathrm{AIC}=$ & 5688.359 & Dif= & 1778.458 & NBRM & PRM & \\
\hline & LRX2= & 1780.455 & Prob= & 0.000 & NBRM & PRM & \\
\hline \multirow[t]{3}{*}{ vs ZIP } & $\mathrm{BIC}=$ & 5597.751 & Dif= & 1922.822 & ZIP & PRM & \multirow[t]{3}{*}{ Muito Forte } \\
\hline & $\mathrm{AIC}=$ & 5490.183 & Dif= & 1976.631 & ZIP & PRM & \\
\hline & Vuong & 18.383 & Prob= & 0.000 & ZIP & PRM & \\
\hline \multirow[t]{2}{*}{ vs ZINB } & $\mathrm{BIC}=$ & 5470.132 & Dif $=$ & 2050.466 & ZINB & PRM & \multirow[t]{2}{*}{ Muito Forte } \\
\hline & $\mathrm{AIC}=$ & 5357.186 & Dif $=$ & 2109.628 & ZINB & PRM & \\
\hline NBRM & $B I C=$ & 5747.522 & $A I C=$ & 5688.359 & Preferido & Sobre & Evidência \\
\hline \multirow[t]{2}{*}{ vs ZIP } & $\mathrm{BIC}=$ & 5597.751 & Dif= & 149.771 & ZIP & NBRM & \multirow[t]{2}{*}{ Muito Forte } \\
\hline & $\mathrm{AIC}=$ & 5490.183 & Dif= & 198.173 & ZIP & NBRM & \\
\hline \multirow[t]{3}{*}{ vs ZINB } & $\mathrm{AIC}=$ & 5470.132 & Dif= & 277.389 & ZINB & NBRM & \multirow[t]{3}{*}{ Muito Forte } \\
\hline & $\mathrm{BIC}=$ & 5357.186 & Dif= & 331.172 & ZINB & NBRM & \\
\hline & Vuong= & 10.256 & Prob= & 0.000 & ZINB & NBRM & \\
\hline ZIP & $B I C=$ & 5597.751 & $A I C=$ & 5490.182 & Preferido & Sobre & Evidência \\
\hline \multirow[t]{3}{*}{ vs ZINB } & $\mathrm{BIC}=$ & 5470.132 & Dif= & 127.619 & ZINB & ZIP & \multirow[t]{3}{*}{ Muito Forte } \\
\hline & $\mathrm{AIC}=$ & 5357.186 & Dif= & 132.997 & ZINB & ZIP & \\
\hline & LRX2= & 134.997 & Prob= & 0.000 & ZINB & ZIP & \\
\hline
\end{tabular}

Fonte: Elaborado pelos autores.

Os resultados para este modelo estão na Tabela 4, e estão diferenciados em seus dois processos inferenciais: o binário (Logit) e o de contagem. A primeira coluna mostra o efeito das variáveis na probabilidade do município não ser passível de cometimento de irregularidades graves, possuindo sempre zero irregularidade do tipo grave. A segunda e terceira colunas mostram respectivamente o coeficiente e o efeito marginal das variáveis 
no modelo de contagem. Como esperado os efeitos das variáveis nestes modelos possuem sinais invertidos dado que suas interpretações vão em sentido contrário (LONG;FREESE, 2003).

Tabela 4 Modelos de Contagem para Achados de Irregularidades Graves

\begin{tabular}{l|rrrr}
\hline \multirow{2}{*}{ Variável } & \multicolumn{3}{c}{ Modelo Zero Inflado Negativo Binomial } \\
\cline { 2 - 4 } & \multicolumn{2}{|c}{ Probabilidade de Zero Infração } & Contagem \\
\cline { 2 - 4 } Controle Social & Coeficiente & Coeficiente & Efeito Marginal \\
\hline \multirow{2}{*}{ Valor Fiscalizado } & 0.4208 & -0.0723 & -0.4899 \\
& $(2.42)$ & $(-0.85)$ & $(-2.73)$ \\
\hline \multirow{2}{*}{ FPM } & -0.0528 & 0.0064 & 0.0597 \\
& $(-4.04)$ & $(2.49)$ & $(4.98)$ \\
\hline \multirow{2}{*}{ IFDM } & 0.0105 & 0.0154 & 0.0189 \\
& $(0,74)$ & $(3.20)$ & $(1.26)$ \\
\hline \multirow{2}{*}{ Vizinhança Corrupta } & 5.6410 & -1.7704 & -8.3755 \\
& $(8.93)$ & $(-6.47)$ & $(-12.15)$ \\
\hline \multirow{2}{*}{ Densidade Demográfica } & -0.3105 & 0.0650 & 0.3962 \\
& $(-2.49)$ & $(1.12)$ & $(2.83)$ \\
\hline \multirow{2}{*}{ Reeleição de Prefeito } & -0.03102 & 0.0037 & 0.0350 \\
\hline \multirow{2}{*}{ Partido Presidente } & $(-2.01)$ & $(1.18)$ & $(2.36)$ \\
\hline \multirow{2}{*}{ Partido Governador } & -0.0056 & 0.0028 & 0.0103 \\
& $(-0.05)$ & $(0.05)$ & $(0.07)$ \\
\hline \multirow{2}{*}{ Constante } & 0.2311 & -0.2386 & -0.5665 \\
& $(-0.85)$ & $(-1.86)$ & $(-2.41)$ \\
\hline Ln (alpha) & -0.2618 & -0.0079 & 0.2205 \\
\hline alpha & $(-1.84)$ & $(-0.13)$ & $(1.37)$ \\
\hline AIC & -28995 & 2.1684 & \\
\hline BIC & $(-7.41)$ & $(13.68)$ & \\
\hline N & & & -1.5778 \\
\hline Fon & & & 0.2064 \\
\hline
\end{tabular}

Fonte: Elaborada pelos autores.

Em geral os resultados do modelo de contagem para achados graves seguem o mesmo padrão de efeito direcional das variáveis com relação aos resultados para os achados médios. No entanto, algumas variáveis perdem 
poder explicativo, como também os efeitos das variáveis significantes possuem magnitudes diferentes ${ }^{25}$, o que reforça o uso de modelos diferenciados no tratamento das irregularidades municipais.

Entre as variáveis que perdem poder explicativo no modelo de achados graves estão o controle social e a presença de um vizinho com muitas irregularidades, ver tabelas 3 e 4 . Vale destacar que as irregularidades graves geralmente implicam diretamente em atos de corrupção com maiores somas de desvios, implicando em ações particularizadas e de informação restrita, o que dificulta tanto a ação do controle social quanto o efeito contágio. Embora as mesmas não tenham sido significantes para a intensidade das irregularidades (contagem), elas o foram para a intenção do cometimento (modelo dual), e mesmo para o cômputo do efeito marginal, que no caso do MNBZI é gerado pela mistura destes dois efeitos (GREENE, 2003). Desta forma, pode-se inferir que o controle social e o efeito vizinhança possuem efeitos moderados na probabilidade de cometimento de infrações graves.

Os demais efeitos das variáveis foram mantidos em seus direcionamentos e significâncias estatísticas em relação ao modelo de irregularidades médias. Ou seja, municípios mais desenvolvidos tendem a apresentar menores irregularidades, e quanto maior for o valor fiscalizado e o FPM, maior será a probabilidade de corrupção no município ${ }^{26}$. As magnitudes de seus efeitos, no entanto, foram menores quando comparados ao modelo de achados médios. Neste caso, uma irregularidade do tipo grave ocorre a cada $\mathrm{R} \$ 16,75$ milhões adicionais recebidos pelo município.

Uma outra forma importante de analisar a tendência de corrupção a partir das transferências é verificar como a probabilidade do município não cometer infração grave diminui com o aumento destas. A Figura 3 mostra exatamente esta relação funcional ${ }^{27}$. A probabilidade de se encontrar zero infração é de $45 \%$ quando se fiscaliza $\mathrm{R} \$ 10$ milhões, e somente de $10 \%$ quando se fiscaliza R \$ 50 milhões. A elasticidade da irregularidade grave com relação ao valor fiscalizado em milhões, na média dos valores, fica em torno de 0,20. Ou seja, se o governo aumentar em média as transferências para os municípios em $10 \%$, o número de irregularidades graves deve aumentar em $2,0 \%$.

25 Vale destacar que esta é uma comparação apenas pontual, não sendo possível estabelecer um teste estatístico de comparação entre as estimativas.

26 As variáveis de reeleição e partido político também não foram significantes no modelo de irregularidades graves.

27 A probabilidade de zero ocorrência grave é dada por $\operatorname{Pr}(y=0)=\pi=(z \delta)+(1-\pi(z \delta)) f_{2}(x \beta)$ e é calculada com as variáveis em seus valores médios, variando apenas a variável de interesse. 
Os resultados relacionados às transferências voluntárias, principalmente com relação ao sinal da variável valor fiscalizado, sugerem a necessidade de adoção de medidas que melhorem os controles internos das prefeituras para todas as fontes de recursos da gestão municipal, o que geraria fortalecimento institucional e influenciaria de forma positiva a eficiência dos gastos públicos no município.

Figura 3 Probabilidade de Não Haver Irregularidades Graves por Valor Recebido

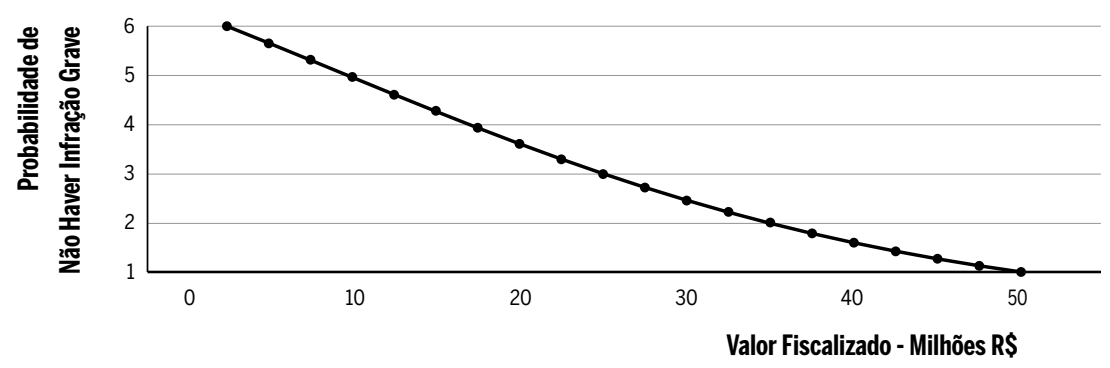

\section{Conclusão}

Este trabalho estimou modelos condicionais de contagem para irregularidades dos tipos médias e graves encontradas pela Controladoria-Geral da União nas transferências voluntárias da União para os municípios brasileiros. Para cada tipo de irregularidade foram testadas e estimadas diferentes especificações dos modelos, onde os melhores encaixes para os dados foram encontrados para modelos negativos binomiais, no caso das irregularidades médias, e modelos negativos binomiais com zeros inflados para as irregularidades graves.

Verificou-se entre outros resultados que os municípios que apresentam tendência à corrupção são aqueles que recebem muitas transferências de recursos, inclusive FPM, que possuem um controle social com fraca atuação, têm baixo nível de desenvolvimento municipal, mas com alta densidade demográfica, e que são vizinhos de municípios com problemas de corrupção. Desta forma, os resultados encontrados estão alinhados com os das principais pesquisas cross-country quanto aos fatores associados à corrupção; quais sejam, fragilidade institucional, nível de renda e fatores educacionais. 
Estimou-se que para cada $\mathrm{R} \$ 100$ milhões a mais recebidos de transferências voluntária, espera-se encontrar 16 irregularidades do tipo média e 6 irregularidades do tipo grave. Embora este efeito pareça ser pequeno, uma irregularidade apenas pode concentrar uma boa parte dos recursos. Ademais, este tipo de transferência investigada, representa apenas uma fração das transferências vinculadas da União para os municípios, onde os desmandos administrativos podem estar mais concentrados.

Os resultados em conjunto mostram que maiores transferências para municípios menos desenvolvidos, com alta densidade e localizados em regiões onde a corrupção é comum, estão associadas a maiores irregularidades, e, portanto, menor eficiência no uso do recurso público. Esta constatação geral possui implicações importantes. Primeiro, do ponto de vista fiscal, são estes os municípios onde o risco de corrupção é maior, e, portanto, podem ter uma atenção especial dos órgãos de controle através de mapeamentos desses municípios, por exemplo. Além disso, embora o programa da CGU estabeleça um sorteio aleatório para atuação nos municípios, pode-se ter ações paralelas de investigação para outros tipos de transferências ou para um período distinto.

Segundo, do ponto de vista das políticas públicas, como a diminuição das transferências não é algo desejável, assim como também não é a redução das despesas públicas, em vista da possibilidade do programa de combate à corrupção poder também inibir a ação de gestão e o estímulo de obtenção de recursos de outro ente da federação, devido ao receio de ser pego e punido (LINCHAND et al. 2016), caberia, então, o fortalecimento das instituições municipais como uma boa alternativa de política.

Dentre os fatores institucionais que deveriam ser trabalhados se destacam as ações da governança municipal, inclusive nos controles internos, na melhoria do processo de aquisições e fortalecimento dos controles sociais. Contudo, sem inibir as decisões dos gestores de prospecção de recursos voluntários e as correspondentes aplicações efetivas no município, principalmente nos municípios que tem nível de dependência fiscal considerável.

\section{Referências}

ACEMOGLU, D; Johnson, S.; Robinson, J. Institutions as the fundamental cause of long-run growth. NBER WP 10481, 2000. Disponível em: <http://www.nber.org/papers/w10481>. Acesso em: 25 mai. 2011. 
ALBUQUERQUE, Emerenciano B.; RAMOS, Francisco S. Análise teórica e empírica dos determinantes de corrupção na gestão municipal pública. Disponível em: <http://www.anpec.org.br/ encontro2006/artigos/A06A030.pdf>. Acesso em: 01 mai. 2016.

AVELINO, G., LORENA, Barberia e BIDERMAN Ciro. Governance in managing public health resources in Brazilian municipalities. Health Policy and Planning, v. 1, p. 1-9, 2013. Disponível em: <http://www.heapol.oxfordjournal.org/content/early/2013/02/13/heapolczt003full $>$. Acesso em: 08 jul. 2016.

BECKER, Gary S. Crime and Punishment: Ana Economic Approach. Journal of Political Econo$m y$, v. 76, n. 2, p. 169-217, 1968.

BARDHAN, P. Corruption and Development: A Review of Issues. Journal of Economic Literature, n. 35, p. 1320-46, 1997.

BARRO, R. J.; SALA-I-MARTIN, Xavier. Economic Growth. MIT Press, 2004.

BROLLO, Fernando; NANNICCINI, Tommaso; PEROTI, Roberto; TABELINI, Guido. "The political resource Curse". American Economic Review, v. 103 (5), p. 1759-96, 2013.

BRUNETTI, Aymo; WEDER, Beatrice. A Free Press is Bad News for Corruption. Journal of Public Economics, v. 87 (7-8), p. 1801-1824, 2003.

CAMERON, A. Colin; TRIVEDI, Pravin K. Microeconometrics Used Stata.Texas, Stata Press Publication, 2009.

CAMERON, A. Colin; TRIVEDI, Pravin K. Microeconometrics: Methods and Applications. Cambridge University Press, 2005.

CAMPOS, Francisco de Assis Oliveira. Três Ensaios sobre a Economia da Corrupção. Fortaleza, 2012. Tese de Doutorado, CAEN/UFC.

CAMPOS, Francisco de Assis Oliveira; PEREIRA, Ricardo A. de Castro. Corrupção e ineficiência no Brasil: Uma análise de equilíbrio geral. Revista Estudos Econômicos, vol. 46, n. 2, SP: 2016.

CARRARO, A.; FOCHEZATTO, A.; HILLBRECHT, R. O Impacto da Corrupção sobre o Crescimento Econômico do Brasil: aplicação de um Modelo de Equilíbrio Geral para o período 1994-1998 - ANPEC, 2006. Disponível em: <http://www.anpec.org.br/encontro2006/artigos/A06A057.pdf>. Acesso em: 22 fev. 2012.

DONCHEV, Dilvan; UJHELVI, Gergely. What Do Corruption Indices Measure? Economics \& Politics, v. 26, 2014.

EASTERLY, Willian. O Espetáculo do Crescimento. Rio de Janeiro: Ediouro, 2004.

FERRAZ, Claudio; FINAN, Frederico; MOREIRA, Diana Bello. Corruption Learning: evidence from missing federal education funds in Brazil. Journal of Public Economics, v. 96, n. 9-10, p. 712-726, 2012.

FERRAZ, Cláudio; FINAN, Frederico. Electoral accountability and corruption: evidence from the audits of local governments. American Economic Review, v. 101, p. 1274-1311, 2011.

GLYNN, Patrik; KOBRIN, Stephen; NAIN, Moisés. A Globalização da Corrupção in ELLIOT, K.A. (ORG.), Corrupção e a Economia Global. Brasília: Editora UNB, 2002.

GREENE, W.H. Econometric Analysis, $5^{\text {a }}$ ed. New Jersey: 2003.

IVANYANA, Maksym; SHAR, Anwar. Decentralization (localization) and Corruption. Policy 
Research Working Paper 5299, The World Bank, may 2010. Disponível em: <http://www. wds.worldbank.org/servlet/WDSContentServer/WDSP/IB/2010/05/10/000158349_2010 0510090347/Rendered/PDF/WPS5299.pdf>. Acesso em: 22 dez. 2011.

KARAHAN Gokhan; RAZZOLINI, Laura; SHUGHART, Willian. No pretense to Honesty: country government corruption in Mississippi. Economic of Governance. v. 7, n. 3, 2006.

KAUFMANN, D; KRAAY, A.; MASTRUZZI, M. Governance Matters III: Governance Indicators for 1996-2002. Policy Research Working Paper Series 3106. Washington, DC: World Bank, 2003.

KLITIGAARD, Robert. A Corrupção Sob Controle. Rio de Janeiro: Jorge Zahar Editor, 1994.

KNACK, Stephen. Measuring Corruption in Eastern Europe and Central Asia: A Critique of the Cross-Country Indicators in World Bank. Policy Research Working Paper 3968, July 2006.

LAMBERT, D. Zero Inflated Poisson Regression with an application to defects in manufacturing. Technometrics, v. 34 (1), p. 1-14, 1992.

LAMBSDORFF, Johann Graf. How Corruption Affects Productivity, Kyklos, 56 (4), 2003.

LICHAND, Guilerme; LOPES, Marcos F.M. e MEDEIROS, Marcelo C. Is Corruption Good For Your Health? Disponível em: <http://www.scholar.harvard.edu/glichand/publications/ job-market-paper. Acesso em: 25 abr. 2016.

LONG, J. S.; FREESE J. Regression Models for Categorical Dependent Variables Using Stata. Rev. ed. College Station, TX: Stata Press, 2003.

MAURO, Paolo. Corruption and Growth. The Quarterly Journal of Economics, n. 442, p. 681-712, august 1995 .

MOCAN, Naci. What Determines Corruption? International Evidence from MicroData. NBER. Working Paper Series 10460, 2004. Disponível em: <http://www.nber.org/papers/ w10460>. Acesso em: 25 jul. 2010.

NEEMAN, Z.; PASERMAN, D; SIMHON A. Corruption and Openness, C.E.P.R. Discussion Papers, n. 4057, 2003.

OLKEN, Benjamin A. Corruption Perceptions vs. Corruption Reality. Journal Of Public Economic, v. 93, n. 7-8, p. 950-964, 2009.

OLSON, Mancur. The logic of collective action: public goods and the theory of groups. Harvard University press, 1965.

REINIKKA, R.; SVENSSON, J. Survey Techniques to Measure and Understand Corruption. Policy Research Working Paper Series: 3071, In: Washington DC: World Bank, 2003.

ROSE-ACKERMAN, Susan. A Economia Política da Corrupção in ELLIOT, KMBERLY ANN (ORG), Corrupção e a Economia Global, Brasília: editora UNB, 2002.

SHLEIFER, Andrei; VISHNY, Robert W. Corruption. Quarterly Journal of Economics, CIX, p. 599-617, 1993.

SVENSSON, J. Eight Questions About Corruption. Journal of Economic Perspective, v. 19, n. 3, p. 19-42, 2005.

TANZI, Vito. Corruption Around the World. IMF Staff Papers, v. 45, p. 559-94, dec. 1998. 
THOMPSON, Theresa; SHAH, Anwar. Transparency International's Corruption Perceptions Index: Whose Perceptions Are They Anyway?, 2005. Disponível em: <http://www.jvi.org/uploads/ tx_abaeasydownloads $1.7 \% 20$ Shah_Thompson_Transparency $\% 20$ international $\% 20$ CPI_whose\%20perceptions \%20are\%20they\%20anyway.pdf>. Acesso em: 28 set. 2009.

TRIBUNAL DE CONTAS DA UNIÃO. Relatório e Parecer Prévio sobre as contas do Governo da República, exercício 2011. Disponível em: <www.tcu.gov.br>. Acesso em: 10 set. 2011.

\section{Sobre os autores}

Francisco de Assis Oliveira Campos - camposfao@gmail.com

Controladoria Geral da União, Fortaleza, Ceará, Brasil.

ORCID: https://orcid.org/0000.0001-8419-0398.

Ivan Castelar - lume1250@yahoo.com

Centro de Aperfeiçoamento de Economistas do Nordeste, Universidade Federal do Ceará, Fortaleza, Ceará, Brasil. ORCID: https://orcid.org/0000-0002-7170-1870.

Ricardo Brito Soares - ricardosoares@caen.ufc.br

Centro de Aperfeiçoamento de Economistas do Nordeste, Universidade Federal do Ceará, Fortaleza, Ceará, Brasil. ORCID: https://orcid.org/0000-0003-2851-4647.

\section{Sobre 0 artigo}

Recebido em 16 de setembro de 2015. Aprovado em 15 de fevereiro de 2017. 


\section{APÊNDICE}

Tabela A1 Distribuição dos Municípios da Amostra

\begin{tabular}{lr}
\hline Estado & Quantidade de Município \\
\hline Acre & 12 \\
\hline Alagoas & 36 \\
\hline Amazonas & 27 \\
\hline Amapá & 12 \\
\hline Bahia & 123 \\
\hline Ceará & 72 \\
\hline Espírito Santo & 25 \\
\hline Goiás & 75 \\
\hline Maranhão & 60 \\
\hline Minas Gerais & 187 \\
\hline Mato Grosso do Sul & 32 \\
\hline Mato Grosso & 32 \\
\hline Pará & 61 \\
\hline Paraíba & 64 \\
\hline Pernambuco & 60 \\
\hline Piauí & 68 \\
\hline Paraná & 90 \\
\hline Rio de Janeiro & 49 \\
\hline Rio Grande do Norte & 62 \\
\hline Rondônia & 22 \\
\hline Roraima & 6 \\
\hline Rio Grande do Sul & 124 \\
\hline Santa Catarina & 74 \\
\hline Sergipe & 32 \\
\hline São Paulo & 151 \\
\hline Tocantins & 44 \\
\hline Son &
\end{tabular}

Fonte: Elaborado pelos autores. 